
JNM
J Neurogastroenterol Motil, Vol. 22 No. 1 January, 2016
pISSN: 2093-0879 elSSN: 2093-0887
http://dx.doi.org/10.5056/jnm15091

\title{
Colonic Hypersensitivity and Sensitization of Voltage-gated Sodium Channels in Primary Sensory Neurons in Rats with Diabetes
}

\author{
Ji Hu, ${ }^{1}$ Zhen-Yuan Song, ${ }^{1,2}$ Hong-Hong Zhang, ${ }^{1,3}$ Xin Qin, ${ }^{1}$ Shufen $\mathrm{Hu}^{3}{ }^{3}$ Xinghong Jiang, ${ }^{3}$ and Guang-Yin Xu ${ }^{3 *}$ \\ ${ }^{I}$ The Second Affiliated Hospital, Soochow University, Suzhou, China; ${ }^{2}$ The East District of Suzhou Municipal Hospital Suzhou, China; and \\ ${ }^{3}$ Jiangsu Key Laboratory of Translational Research and Therapy for Neuro-Psycho-Diseases, Institute of Neuroscience, Soochow University, \\ Suzhou, China
}

\section{Background/Aims}

Patients with long-standing diabetes often demonstrate intestinal dysfunction and abdominal pain. However, the pathophysiology of abdominal pain in diabetic patients remains elusive. The purpose of study was to determine roles of voltage-gated sodium channels in dorsal root ganglion (DRG) in colonic hypersensitivity of rats with diabetes.

\section{Methods}

Diabetic models were induced by a single intraperitoneal injection of streptozotocin (STZ; $65 \mathrm{mg} / \mathrm{kg}$ ) in adult female rats, while the control rats received citrate buffer only. Behavioral responses to colorectal distention were used to determine colonic sensitivity in rats. Colon projection DRG neurons labeled with DiI were acutely dissociated for measuring excitability and sodium channel currents by whole-cell patch clamp recordings. Western blot analysis was employed to measure the expression of $\mathrm{Na}_{\vee} 1.7$ and $\mathrm{Na}_{v} 1.8$ of colon DRGs.

\section{Results}

STZ injection produced a significantly lower distention threshold than control rats in responding to colorectal distention. STZ injection also depolarized the resting membrane potentials, hyperpolarized action potential threshold, decreased rheobase and increased frequency of action potentials evoked by 2 and 3 times rheobase and ramp current stimulation. Furthermore, STZ injection enhanced neuronal sodium current densities of DRG neurons innervating the colon. STZ injection also led to a significant upregulation of $\mathrm{Na}_{\mathrm{V}} 1.7$ and $\mathrm{Na}_{\mathrm{v}} 1.8$ expression in colon DRGs compared with age and sex-matched control rats.

\section{Conclusions}

Our results suggest that enhanced neuronal excitability following STZ injection, which may be mediated by upregulation of $\mathrm{Na}_{\mathrm{V}} 1.7$ and $\mathrm{Na}_{\mathrm{v}} 1.8$ expression in DRGs, may play an important role in colonic hypersensitivity in rats with diabetes.

(J Neurogastroenterol Motil 2016;22:129-140)

Key Words

Colonic hypersensitivity; Diabetes; Dorsal root ganglion; Voltage-gated sodium channels

Received: June 1, 2015 Revised: August 3, 2015 Accepted: August 18, 2015

(.) This is an Open Access article distributed under the terms of the Creative Commons Attribution Non-Commercial License (http://creativecommons. org/licenses/by-nc/4.0) which permits unrestricted non-commercial use, distribution, and reproduction in any medium, provided the original work is properly cited.

${ }^{*}$ Correspondence: Guang-Yin Xu, MD, PhD

Laboratory for Translational Pain Medicine, Institute of Neuroscience, Soochow University, 199 Ren-Ai Road, Suzhou 215123, China

Tel: +86-512-65882817, Fax: +86-512-65883602, E-mail: guangyinxu@suda.edu.cn

Ji Hu and Zhen-Yuan Song contributed equally to this work. 


\section{Introduction}

Intestinal dysfunction is a common chronic complication of diabetes mellitus. Many patients exhibit symptoms such as abdominal pain or discomfort, rectal urgency, and altered bowel habits. ${ }^{1,2}$ It affects the quality of patients' daily life since the treatment options are very limited. The etiology of intestinal complications of diabetes is multifactorial. There is growing evidence indicating that autonomic neuropathy is an important causal factor in gastrointestinal dysfunction of diabetes. ${ }^{3,4}$ Moreover, several studies suggest that abdominal pain or discomfort in patients with diabetes may be the consequence of enhanced activity of primary afferent fibers leading to an increased excitatory tone in the spinal cord. ${ }^{5,6}$ However, the mechanism underlying these changes in the primary sensory neurons in colonic hypersensitivity of diabetes is not well known.

Increased ectopic discharges of primary sensory neurons are the electrophysiological bases of neuropathic pain in diabetes ${ }^{7}$ and changes of ion channel activities in dorsal root ganglion (DRG) neurons play a significant role in the generation of peripheral sensitization and nociceptive sensation. ${ }^{6}$ Grabauskas et $\mathrm{al}^{6}$ found that colonic hypersensitivity is associated with decreased opening of $\mathrm{K}_{\mathrm{V}} 4.2$ channels in rats with diabetes. However, roles for voltage-gated sodium channels (VGSCs) in colonic hypersensitivity of diabetes are not clear. Two isoforms of the $\alpha$-subunit of VGSCs, $\mathrm{Na}_{\mathrm{V}} 1.7$, and $\mathrm{Na}_{\mathrm{v}} 1.8$, are expressed at high levels in nociceptive sensory neurons. ${ }^{8}$ Multiple lines of evidence show that they have been implicated in the development of inflammatory pain ${ }^{9,10}$ and neuropathic pain. ${ }^{11-13}$ Furthermore, dysregulation of VGSCs in injured sensory neurons is also involved in the development of painful peripheral neuropathy in a rat model of diabetes. ${ }^{14-17}$ However, roles for $\mathrm{Na}_{\mathrm{V}} 1.7$ and $\mathrm{Na}_{\mathrm{V}} 1.8$ in colonic hypersensitivity in streptozotocin (STZ)-induced diabetic rats remain unknown.

Therefore, we hypothesized that colonic hypersensitivity correlated with sensitization of VGSCs in DRG neurons innervating the colon in rat with diabetes. To test this hypothesis, we examined expressions of $\mathrm{Na}_{\mathrm{V}} 1.7$ and $\mathrm{Na}_{\mathrm{V}} 1.8$ protein and recorded sodium channel currents in DRG neurons innervating the colon of control and STZ-induced diabetic rats.

\section{Materials and Methods}

\section{Induction of Streptozotocin-induced Diabetes}

Female Sprague-Dawley rats (160-180 g) were used in our experiments. The holding room was temperature controlled (25 \pm $1^{\circ} \mathrm{C}$ ) and under a 12-hour light/dark cycle. Rats were allowed access to tap water and standard laboratory chow ad libitum. All experiments were in accordance with the guidelines of the International Association for the Study of Pain and were approved by the Institutional Animal Care and Use Committee of Soochow University.

Rats were fasted overnight and then intraperitoneally injected with STZ (65 mg/kg; Sigma, St. Louis, MO, USA). STZ was freshly dissolved in citrate buffer $(10 \mathrm{mmol} / \mathrm{L}, \mathrm{Na}$ citrate, $\mathrm{pH}$ 4.34.4). The control (CON) rats only received an equivalent volume of citrate buffer. One week later, diabetes was confirmed by measuring the blood glucose concentration obtained from the tail vein with glucometer (Johnson \& Johnson, New Brunswick, NJ, USA). The rats with blood glucose level greater than $15 \mathrm{mmol} / \mathrm{L}$ (270 mg/ $\mathrm{dL}$ ) were used in the present experiments. ${ }^{18}$ Body weights of all rats were measured by an electronic weighing scale.

\section{Behavioral Test for Nocifensive Responses to Colorectal Distention}

Colonic hypersensitivity was measured by observing the response of rats to colorectal distention (CRD) as described in details previously. ${ }^{19,20}$ The rats were anesthetized with mild sedation (1\% Brevital, $25 \mathrm{mg} / \mathrm{kg}$ intraperitoneal [i.p.]). A balloon made from a surgical glove finger was attached to tygon tubing. After lubrication with vaseline, the balloon was inserted $8 \mathrm{~cm}$ into the rectum and descending colon via the anus. Rats were then placed individually in a small plastic cage by taping the tubing to the tail and allowed to adapt for 30 minutes. Distention threshold (DT), the minimal distention pressure to induce abdominal muscle contraction, was measured. ${ }^{21}$ By quickly inflating the balloon to a constant pressure, DT was recorded in millimeters mercury $(\mathrm{mmHg})$ using a sphygmomanometer. Investigators were blinded while measuring DT, and each measurement was performed twice. At the end of each experiment, the balloon was carefully removed and the rat was returned to housing. The behavioral test was performed once every 2 weeks.

\section{Cell Retrograde Labeling}

As described previously, ${ }^{20,22}$ DRG neurons innervating the colon were labeled by injection of fluorescent dye DiI (Invitrogen, New York, NY, USA) into the colon wall. Rats were anesthetized with chloral hydrate $(0.36 \mathrm{~g} / \mathrm{kg}$ i.p.), and their abdomen was opened and the colon was exposed. DiI ( $20 \mathrm{mg}$ in $0.5 \mathrm{~mL}$ methanol) was injected in a $0.1 \mu \mathrm{L}$ volume at 10 sites of the exposed descending colon. The colon was washed and swabbed with normal saline before closing the abdomen. One week later, rats were given STZ 
or citrate buffer injection intraperitoneally. Four weeks later, DRG neurons (T13-L2) innervating the colon were dissected out for patch-clamp recordings.

\section{Dissociation of Dorsal Root Ganglion Neurons}

Bilateral DRGs (T13-L2) were dissected out from anesthetized rats and transferred to an ice-cold, oxygenated fresh dissecting solution. After removal of the connective tissue, the ganglia were incubated for 1.5 hours at $34.5^{\circ} \mathrm{C}$ in a $5-\mathrm{mL}$ dissecting solution containing trypsin $(1.5 \mathrm{mg} / \mathrm{mL}$; Sigma) and collagenase D (2.0$2.2 \mathrm{mg} / \mathrm{mL}$; Roche, Indianapolis, IN, USA). After being taken out from the enzyme solution, DRGs were washed and dispersed by repeated trituration through Pasteur pipettes. A single cell suspension was transferred onto glass cover slips for 30 minutes. The rats were euthanized after DRG dissection.

\section{Whole-cell Patch Clamp Recordings}

To determine whether DRG neurons are involved in the development of colonic hypersensitivity in STZ rats, we measured the excitability of DRG neurons innervating the colon by whole-cell patch-clamp recording techniques. As described previously, ${ }^{23}$ cover slips containing adherent DRG cells were superfused with normal external solution at room temperature $\left(25^{\circ} \mathrm{C}\right)$. Small and mediumsized DRG neurons were chosen in our study, because they are responsible for pain sensation. ${ }^{24,25}$ The voltage was clamped at -60 $\mathrm{mV}$. Whole cell current and voltage were recorded with a HEKA EPC10 patch-clamp amplifier. The data were acquired and stored on a computer and analyzed by Fit Master from HEKA. Cells were characterized by cell membrane capacitance $\left(\mathrm{C}_{\mathrm{m}}\right)$, input resistance $\left(\mathrm{R}_{\text {in }}\right)$, resting membrane potential $(\mathrm{RP})$, rheobase, action potential (AP) threshold, AP overshoot, and duration elicited by current stimulation. The frequency of APs stimulated by $2 \times$ and $3 \times$ rheobase and ramp current stimulation $(0.1,0.3,0.5$, and 1.0 $\mathrm{nA} / \mathrm{sec}$ ramp current) was recorded under the current clamp mode.

\section{Isolation of $\mathrm{Na}_{\mathrm{V}}$ Currents}

Changes in AP frequency and activation thresholds suggest an alteration in $\mathrm{Na}_{\mathrm{V}}$ channels. ${ }^{26-28}$ We next performed patch-clamp recordings to examine sodium current under voltage-clamped conditions. Cells were superfused with an external solution, containing (in $\mathrm{mM}$ ): $60 \mathrm{NaCl}, 80$ choline chloride, $0.1 \mathrm{CaCl}_{2}, 10$ HEPES, 10 tetraethylammonium chloride, 10 glucose, and $0.1 \mathrm{CdCl}_{2}(\mathrm{pH}$ 7.4, adjusted with tetraethylammonium hydroxide; osmolarity, 310 $\mathrm{mOsm} / \mathrm{kg} \mathrm{H} \mathrm{H}_{2} \mathrm{O}$ ). The patch electrode had a resistance of 4-7 $\mathrm{M} \Omega$ when filled with the pipette solution containing (in $\mathrm{mM}$ ): $140 \mathrm{CsF}$,
$1 \mathrm{MgCl}_{2}$, 5 EGTA, 3 Na-GTP, 10 glucose, and 10 HEPES (pH 7.2, adjusted with $\mathrm{CsOH}$; osmolarity, 285-295 mOsm/ $\mathrm{kg} \mathrm{H} \mathrm{H}_{2} \mathrm{O}$ ). The sodium currents were isolated by blocking the $\mathrm{K}^{+}$and $\mathrm{Ca}^{2+}$ currents with appropriate ion replacements and channel blockers. ${ }^{29}$ $\mathrm{K}^{+}$in the control external solution was replaced with tetraethylammonium and the $\mathrm{Ca}^{2+}$ concentration reduced to $0.1 \mathrm{mM}$. Cs ${ }^{+}$ in the internal solution was used to block $\mathrm{K}^{+}$current and the $\mathrm{F}^{-}$ was used to maintain the stability of sodium currents and very low concentration of calcium $(0.1 \mathrm{mM})$ also can block some $\mathrm{Ca}^{2+}$ currents. ${ }^{30,31}$ The $\mathrm{Na}_{\mathrm{V}}$ currents were recorded in response to every stimulation potential from -70 to $+50 \mathrm{mV}$ in $10 \mathrm{mV}$ increments. The peak sodium current was measured as the peak of the current at every given voltage. In order to control the differences in cell size, the current densities $(\mathrm{pA} / \mathrm{pF})$ was measured by dividing the current amplitude by cell membrane capacitance.

\section{Western Blot}

Expressions of $\mathrm{Na}_{\mathrm{v}} 1.7$ and $\mathrm{Na}_{\mathrm{V}} 1.8$ in T13-L2 DRGs from STZ-induced diabetic rats and CON rats were measured using western blotting analyses. T13-L2 DRGs were dissected out and lysed in MT-CelLytics mammalian tissue protein extraction reagent with PIC (1:100 dilution of protease inhibitor cocktail; Biocolor BioScience \& Technology Company, Shanghai, China). The cell lysates were microfuged at $15000 \mathrm{rpm}$ for 25 minutes at $4^{\circ} \mathrm{C}$. The proteins were fractionated on $8 \%$ polyacrylamide gels (Bio-Rad, Hercules, CA, USA). After electrophoresis, proteins were transferred to polyvinyldifluoride membranes (Roche) at $200 \mathrm{~mA}$ for 5 hours at $4^{\circ} \mathrm{C}$. The membranes were blocked with $5 \%$ non-fat dry milk in tris buffered saline for 2 hours at room temperature and then incubated with the primary antibodies (rabbit anti- $\mathrm{Na}_{\mathrm{V}} 1.7$ or anti- $\mathrm{Na}_{\mathrm{V}} 1.8$ [1:200], Alomone Labs, Jerusalem, Israel; rabbit anti-glyceraldehyde3-phosphate dehydrogenase [GAPDH] [1:1000], Biotechnology Co, Hangzhou, China and mouse anti-actin [1:1000], Chemicon, Temecula, CA, USA) overnight at $4^{\circ} \mathrm{C}$. After being washed in tris buffered saline containing $0.5 \%$ Tween-20, membranes were incubated with anti-rabbit peroxidase-conjugated secondary antibody (1:2000; Santa Cruz Biotechnology, Santa Cruz, CA, USA) or anti-mouse horseradish peroxidase-conjugated secondary antibody (1:4000; Chemicon) for 2 hours at room temperature. The immunoreactive proteins were detected by enhanced chemiluminescence (ECL kit; GE Healthcare Pharmacia Biotech, Shanghai, China) and images were acquired with a scanner (GelDoc XRS imaging system, Bio-Rad). The densities of protein bands were analyzed using NIH Image software. The band intensities of $\mathrm{Na}_{\mathrm{v}} 1.7$ and $\mathrm{Na}_{v} 1.8$ were normalized to intensities of $\beta$-actin or GAPDH. 


\section{Statistical Methods}

DRG neurons with RP greater than $-40 \mathrm{mV}$ were excluded from the data analysis since these neurons were considered to be under unhealthy conditions. All data were expressed as means \pm SEM. Statistical analysis was performed using software OriginPro 8 (OriginLab Co, Northampton, MA, USA). Normality was first checked for all data before analysis. Significance was determined using two-sample $t$ test, Mann-Whitney test or two-way repeatedmeasures ANOVA followed by Tukey post hoc test, as appropriate. Results were considered statistically significant when the $P$-value was less than 0.05 .

\section{Results}

\section{Streptozotocin Injection Induced Colonic Hypersen- sitivity}

After a single intraperitoneal injection of STZ, body weights

A

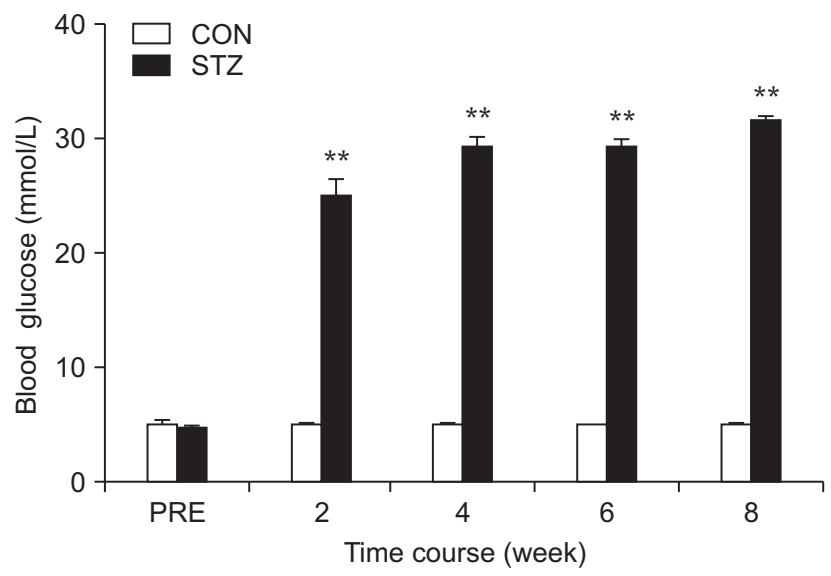

C

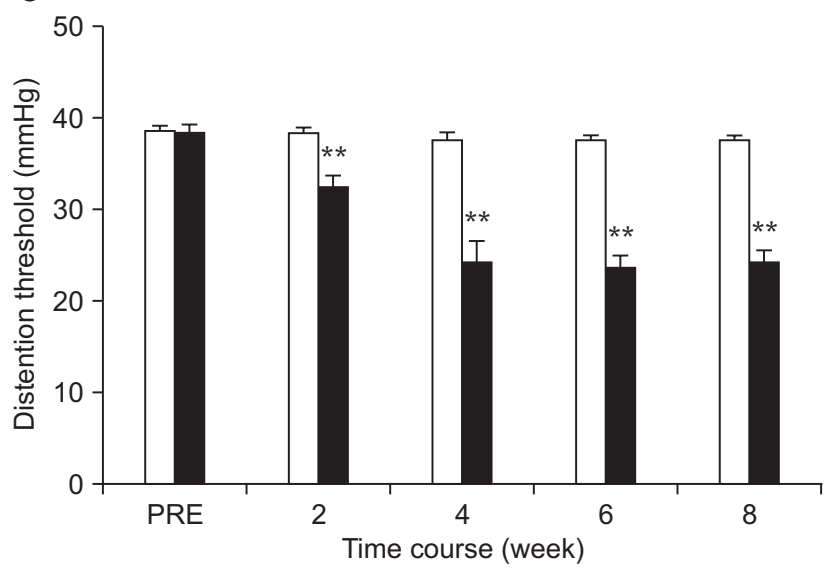

and blood glucose levels were measured every 2 weeks until 8 weeks after the injection. Compared with $\mathrm{CON}$ rats, the majority of rats developed hyperglycemia and displayed polyuria with increasing food and water intake. Blood glucose levels were elevated 2 weeks after STZ injection and maintained at a high level for at least another 6 weeks (Fig. 1A; $n=8$ for each group, $P<0.01$, compared with $\mathrm{CON}$, two-way repeated-measures ANOVA followed by Tukey post hoc test). The growth rate of STZ rats was remarkably reduced compared with $\mathrm{CON}$ rats (Fig. $1 \mathrm{~B} ; \mathrm{n}=8$ for each group, $P<0.01$, compared with $\mathrm{CON}$, two-way repeated-measures ANOVA followed by Tukey post hoc test). In parallel with elevated blood glucose levels, STZ-induced rats also developed colonic hypersensitivity as shown by measuring the DT in response to CRD. The DT was significantly decreased at 2 weeks after STZ injection and lasted for 6 weeks within our observation time period (Fig. 1C; $\mathrm{n}=8$ for each group, $P<0.01$, compared with CON, two-way repeated-measures ANOVA followed by Tukey post hoc test).

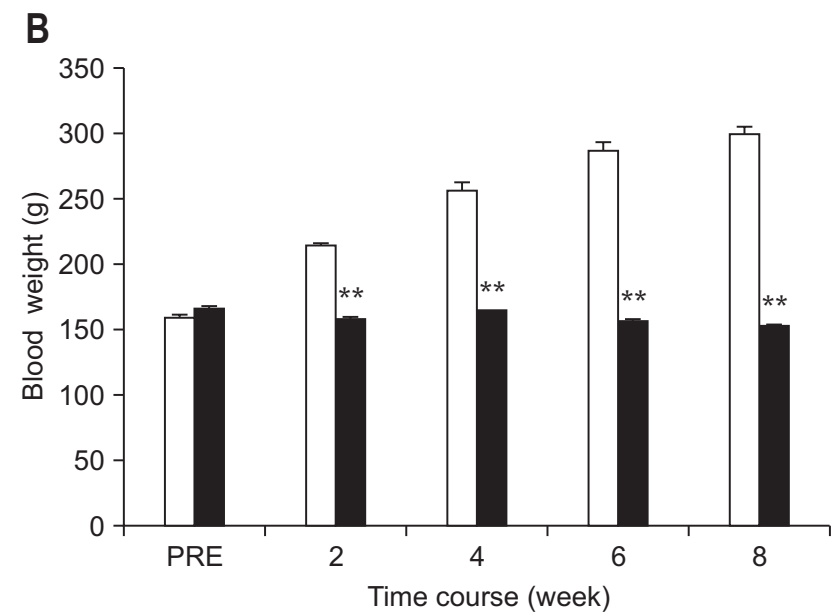

Figure 1. Colonic hypersensitivity in streptozotocin (STZ)-induced diabetic rats. (A) Following a single intraperitoneal injection of STZ, the blood glucose level was significantly increased. The hyperglycemia persisted for at least another 6 weeks within our observation period of time ( $\mathrm{n}=8$ for both groups, ${ }^{*} P<0.01$ compared with control $(\mathrm{CON})$, two-way repeated-measures ANOVA followed by Tukey post hoc test). (B) The growth rate of STZ rats was reduced. The body weight of CON rats exhibited a steady increase, whereas STZ rats remained unchanged in body weight $\left(\mathrm{n}=8\right.$ for both groups, ${ }^{* *} P<0.01$, compared with CON, two-way repeated-measures ANOVA followed by Tukey post hoc test). (C) Time course of changes in distention threshold (DT) in response to colorectal distention. STZ injection significantly reduced the DT at 2 weeks and lasted for another 6 weeks ( $\mathrm{n}=8$ for both groups, ${ }^{*} P<0.01$, compared with $\mathrm{CON}$, two-way repeated-measures ANOVA followed by Tukey post hoc test). PRE, before injection of STZ or citrate buffer $(\mathrm{CON})$. 


\section{Streptozotocin Injection Enhanced Excitability of Dorsal Root Ganglion Neurons}

DRG neurons innervating the colon were labeled by the fluorescent dye DiI (Fig. 2A, arrow). As shown in Table, we observed a significant depolarization in the RP of DRG neurons innervating the colon in STZ-induced diabetic rats (Fig. $2 \mathrm{~B} ; P<0.01$, compared with CON, Mann-Whitney test). AP threshold was hyperpolarized in the STZ group when compared with the CON group (Fig. $2 \mathrm{C} ; P<0.01$, compared with $\mathrm{CON}$, two-sample $t$ test). Rheobase, the minimal injected current that evokes one AP, was much lower in the STZ group than in the CON group (Fig. 2D; $P<0.01$, compared with CON, Mann-Whitney test). The frequency of APs in response to 2 times $(2 \times)$ and 3 times rheobase $(3 \times)$ current stimulation was significantly increased in DRG neurons from STZ-induced diabetic rats (Fig. 2E and 2F, MannWhitney test and two-sample $t$ test).

The frequencies of APs in response to $0.3,0.5$, and $1.0 \mathrm{nA}$
A
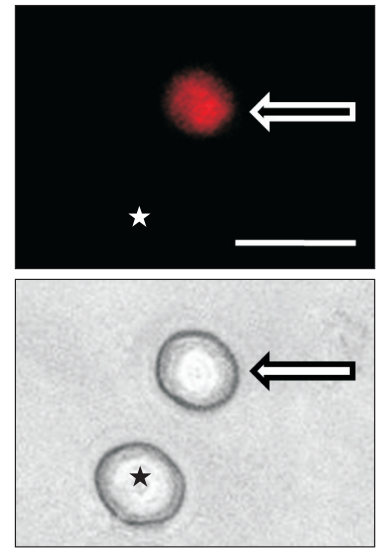

B

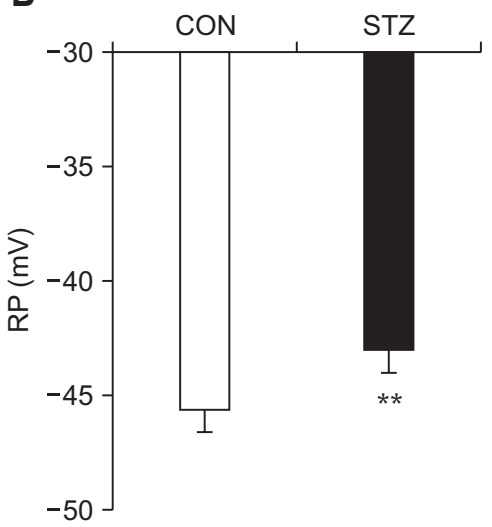

C

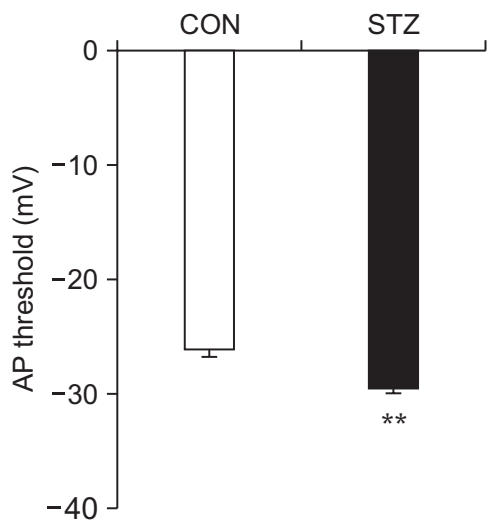

D

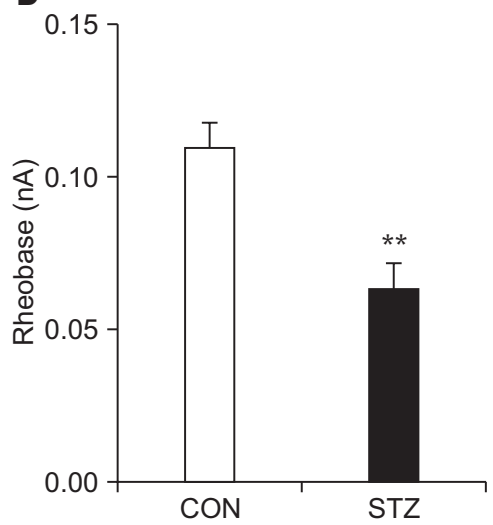

E

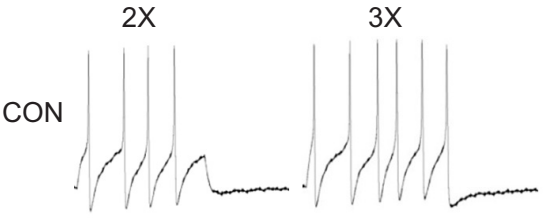

ㄹ

STZ

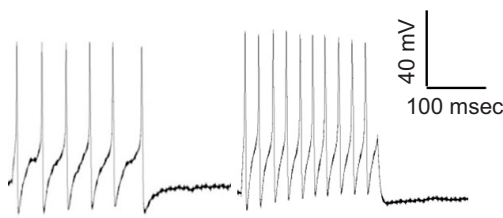

$\mathbf{F}$

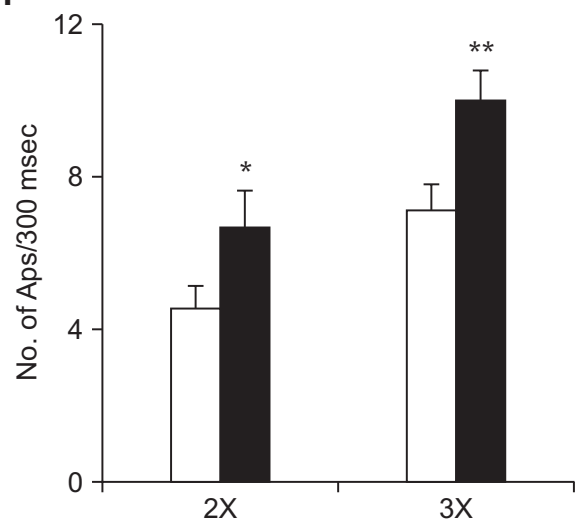

Figure 2. Changes in membrane properties of colon projection dorsal root ganglion (DRG) neurons 4 weeks after streptozotocin (STZ) injection. (A) Top: an example of a Dil-labeled DRG neuron (arrow). Asterisk indicates the place where a neuron is not labeled by DiI. Bottom: phase image of the same DRG neuron labeled by DiI is shown on the right (arrow) and the neuron not labeled by DiI is shown on the left ( $\star$ ). Scale bar $=50 \mu \mathrm{m}$. Patch-clamp recordings were performed on DiI-labeled colon neurons. A total of 25 DiI-labeled neurons from control (CON) rats and 25 DiI-labeled neurons from STZ-induced diabetic rats were recorded under current-clamp conditions. (B) STZ injection depolarized the resting membrane potential (RP) in DiI-labeled DRG neurons ( ${ }^{*} P<0.01$, compared with CON, Mann-Whitney test). (C) STZ injection remarkably hyperpolarized action potential (AP) threshold $\left({ }^{*} P<0.01\right.$, compared with CON, two-sample $t$ test). (D) STZ injection resulted in a marked reduction of rheobase ( ${ }^{* *} P<0.01$, compared with $\mathrm{CON}$, Mann-Whitney test). (E) Examples of AP trances evoked by $2 \times$ (left) and $3 \times$ (right) rheobase current stimulation of DRG neurons from CON (top) and STZ-injected rats (bottom). (F) Bar graphs showed that STZ injection greatly increased frequencies of APs evoked by $2 \times$ and $3 \times$ rheobase current stimulation $\left({ }^{*} P<0.05,{ }^{* *} P<0.01\right.$, compared with CON, Mann-Whitney test and two-sample $t$ test). 
Table. Membrane Characteristics of Colon Projection Dorsal Root Ganglion Neurons in Control and Streptozotocin-induced Diabetic Rats

\begin{tabular}{lrrr} 
& CON & STZ & $P$-value \\
\hline Cell Size $(\mu \mathrm{m})$ & $25.4 \pm 0.5(\mathrm{n}=25)$ & $26.2 \pm 0.5(\mathrm{n}=25)$ & 0.257 \\
$\mathrm{C}_{\mathrm{m}}(\mathrm{pF})$ & $28.9 \pm 1.1(\mathrm{n}=25)$ & $26.4 \pm 1.0(\mathrm{n}=25)$ & 0.088 \\
$\mathrm{R}_{\mathrm{in}}(\mathrm{M} \Omega)$ & $553.8 \pm 38.7(\mathrm{n}=25)$ & $613.5 \pm 40.0(\mathrm{n}=25)$ & 0.303 \\
$\mathrm{RP}(\mathrm{mV})$ & $-45.6 \pm 0.7(\mathrm{n}=25)$ & $-43.0 \pm 0.4(\mathrm{n}=25)$ & $<0.01$ \\
Rheobase $(\mathrm{nA})$ & $0.11 \pm 0.01(\mathrm{n}=25)$ & $0.06 \pm 0.01(\mathrm{n}=25)$ & $<0.001$ \\
No. of APs $(2 \times)$ & $4.4 \pm 0.3(\mathrm{n}=25)$ & $6.1 \pm 0.7(\mathrm{n}=25)$ & $<0.05$ \\
No. of APs $(3 \times)$ & $6.6 \pm 0.5(\mathrm{n}=25)$ & $9.9 \pm 1.1(\mathrm{n}=25)$ & $<0.01$ \\
AP Threshold $(\mathrm{mV})$ & $-26.1 \pm 0.9(\mathrm{n}=25)$ & $-29.7 \pm 0.6(\mathrm{n}=25)$ & $<0.01$ \\
AP Overshoot $(\mathrm{mV})$ & $42.9 \pm 1.8(\mathrm{n}=25)$ & $38.0 \pm 1.8(\mathrm{n}=25)$ & 0.058 \\
AP Duration $(\mathrm{msec})$ & $2.7 \pm 0.1(\mathrm{n}=25)$ & $2.3 \pm 0.2(\mathrm{n}=25)$ & 0.060 \\
No. of APs $(0.1 \mathrm{nA})$ & $2.0 \pm 0.6(\mathrm{n}=21)$ & $6.5 \pm 1.1(\mathrm{n}=23)$ & 0.104 \\
No. of APs $(0.3 \mathrm{nA})$ & $7.1 \pm 1.0(\mathrm{n}=21)$ & $17.8 \pm 2.2(\mathrm{n}=23)$ & $<0.001$ \\
No. of APs $(0.5 \mathrm{nA})$ & $17.5 \pm 1.8(\mathrm{n}=21)$ & $30.7 \pm 2.4(\mathrm{n}=23)$ & $<0.001$ \\
No. of APs $(1.0 \mathrm{nA})$ & $33.7 \pm 2.2(\mathrm{n}=21)$ & $54.4 \pm 3.4(\mathrm{n}=23)$ & $<0.001$ \\
TTFS (msec, $0.1 \mathrm{nA})$ & $845.5 \pm 45.9(\mathrm{n}=21)$ & $650.1 \pm 57.8(\mathrm{n}=23)$ & $<0.001$ \\
TTFS (msec, $0.3 \mathrm{nA})$ & $581.7 \pm 44.0(\mathrm{n}=21)$ & $451.3 \pm 50.6(\mathrm{n}=23)$ & $<0.05$ \\
TTFS (msec, $0.5 \mathrm{nA})$ & $325.9 \pm 20.7(\mathrm{n}=21)$ & $302.0 \pm 27.6(\mathrm{n}=23)$ & 0.714 \\
TTFS (msec, $1.0 \mathrm{nA})$ & $182.3 \pm 12.2(\mathrm{n}=21)$ & $187.4 \pm 20.6(\mathrm{n}=23)$ & 0.854 \\
\hline
\end{tabular}

$\mathrm{C}_{\mathrm{m}}$, membrane capacitance; $\mathrm{R}_{\mathrm{in}}$, input resistance; RP, resting membrane potential; AP, action potential; TTFS, time to first spike.

Values are mean \pm SEM, with sample size in parenthesis. $P$-values were determined by two-sample $t$ test, Mann-Whitney test or two-way repeated-measures ANOVA followed by Tukey post hoc test where appropriate.

ramp current stimulation was greatly increased in STZ-induced diabetic rats compared with $\mathrm{CON}$ rats (Fig. $3 \mathrm{~A}$ and $3 \mathrm{~B}$; $P<$ 0.01, compared with CON, two-way repeated-measures ANOVA followed by Tukey post hoc test). Furthermore, at 0.1 and $0.3 \mathrm{nA}$ stimulations, the time to first spike (TTFS) was remarkably short in rats with diabetes (Fig. 3C; $P<0.05, P<0.01$, two-way repeatedmeasures ANOVA followed by Tukey post hoc test), but at 0.5 and $1.0 \mathrm{nA}$ stimulations, TTFS did not alter after STZ injection (Fig. $3 \mathrm{C}$; at the $0.5 \mathrm{nA}$ stimulation, $P>0.05$, two-way repeated measures ANOVA followed by Tukey post hoc test).

There was no significant difference in cell membrane capacitance $\left(\mathrm{C}_{\mathrm{m}}\right)$, input resistance $\left(\mathrm{R}_{\mathrm{in}}\right)$, AP duration (at $0 \mathrm{mV}$ ) and AP overshoot of DRG neurons innervating the colon in rats after STZ injection (Table).

\section{Streptozotocin Injection Increased Sodium Current Densities of Dorsal Root Ganglion Neurons}

Figure 4A shows examples of VGSCs recorded from CON and STZ-treated rats. The membrane potential was held at -60 $\mathrm{mV}$ and depolarization steps from $-70 \mathrm{mV}$ to $+50 \mathrm{mV}$ in $10 \mathrm{mV}$ increments with duration of 80 milliseconds were used to activate $\mathrm{Na}_{\mathrm{V}}$ channels. The amplitude of sodium current increased in STZ rats. The peak current-voltage (I-V) curves are shown in Figure
4B. STZ injection markedly increased the average of peak sodium current densities in DiI labeled neurons compared with the CON group $(\mathrm{CON}:-53.99 \pm 3.50 \mathrm{pA} / \mathrm{pF}, \mathrm{n}=14$; STZ: $-79.48 \pm$ $10.54 \mathrm{pA} / \mathrm{pF}, \mathrm{n}=14 ; P<0.05$, Mann-Whitney test) (Fig. 4C).

We next analyzed the dynamic modification of activation and inactivation responses of sodium currents. Activation of the currentvoltage relationship was constructed from I-V curves of neurons from CON and STZ-injected rats. STZ injection did not change the activation curve compared with CON (Fig. 4D). At different test potentials, membrane conductance $(G)$ was measured by dividing the peak sodium current by the current driving force ( $\mathrm{Vm}$ Vrev) and was normalized to that recorded at $+30 \mathrm{mV}$ (Gmax). Data were fitted with the following modified Boltzmann equation: $\mathrm{G} / \mathrm{Gmax}=1 /\left\{1+\exp \left[-\left(\mathrm{V}-\mathrm{V}_{1 / 2}\right) / \mathrm{k}\right]\right\}$, where $\mathrm{V}$ is membrane potential, $V_{1 / 2}\left(V_{\text {half }}\right)$ is the membrane voltage at which the current was half-maximally activated, and $\mathrm{k}$ is the slope factor. ${ }^{31}$ Both $\mathrm{V}_{1 / 2}$ and $\mathrm{k}$ did not change significantly after STZ injection $(P>0.05$, compared with CON, Mann-Whitney test) (Fig. 4E and 4F). Furthermore, we studied the effect of hyperglycemia on the voltage dependence of steady-state inactivation of sodium channels of colon projection DRG neurons. The membrane potential was held at $-60 \mathrm{mV}$ and voltage steps were from $-90 \mathrm{mV}$ to $+30 \mathrm{mV}$ with $10 \mathrm{mV}$ increments and 80 milliseconds in duration. For steady-state 

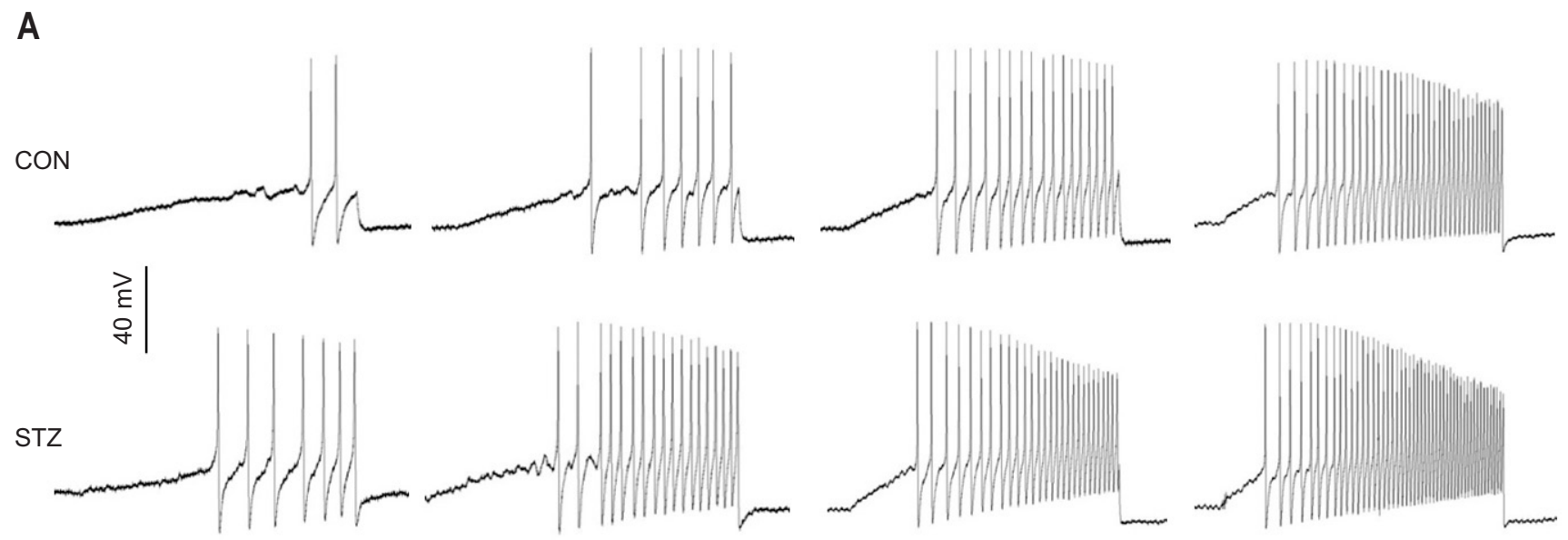

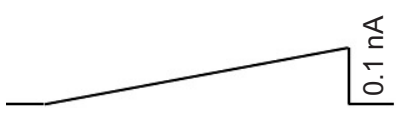

$1000 \mathrm{msec}$

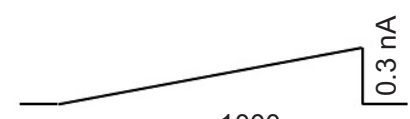

$1000 \mathrm{msec}$

\section{B}

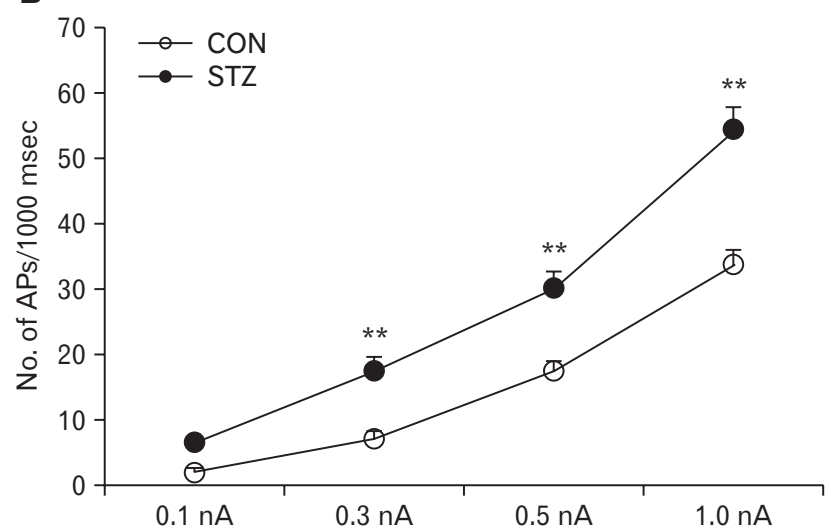

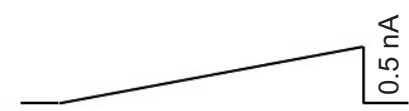

$1000 \mathrm{msec}$

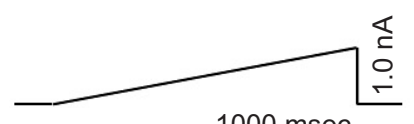

$1000 \mathrm{msec}$

C

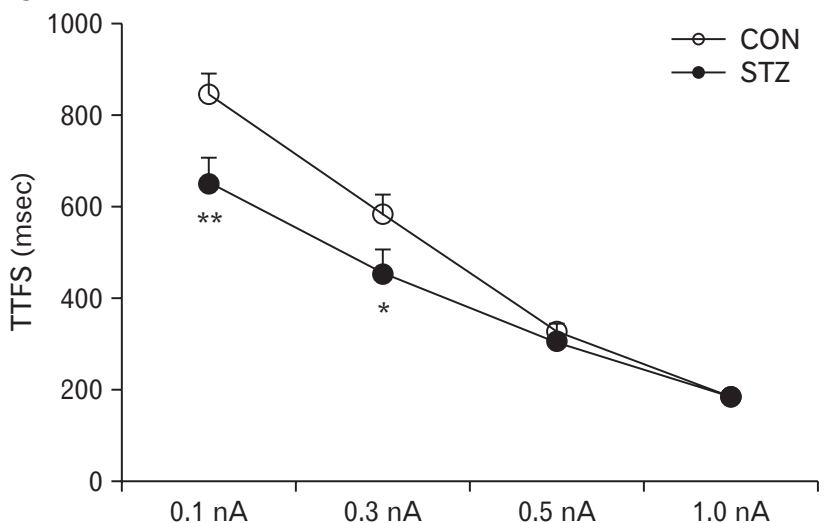

Figure 3. Increased frequencies of action potentials (APs) evoked by ramp current stimulation in rats with diabetes 4 weeks after streptozotocin (STZ) injection. (A) Examples of APs by $0.1,0.3,0.5$, and $1.0 \mathrm{nA}$ ramp current injection from control (CON) and STZ rats. (B) Line chart showed a significant increase in frequencies of APs evoked by $0.3,0.5$, and $1.0 \mathrm{nA}$ ramp current stimulation in CON and STZ-induced diabetic rats ( $* * P<0.01$, compared with CON, two-way repeated-measures ANOVA followed by Tukey post hoc test). (C) Line chart showed the mean time to first spike (TTFS) in response to $0.1,0.3,0.5$, and $1.0 \mathrm{nA}$ ramp current stimulation from CON or STZ-induced diabetic rats $\left({ }^{*} P<0.05\right.$, ${ }^{* *} \mathrm{P}<0.01$, compared with CON, two-way repeated-measures ANOVA followed by Tukey post hoc test).

inactivation curves, the peak current amplitudes were normalized to those recorded at a $90 \mathrm{mV}$ conditioning step (Imax). STZ injection did not alter the inactivation curve compared with CON (Fig. 4G). Data were plotted as a function of conditional step potentials and fitted with the following negative Boltzmann equation: I/Imax = $1 /\left\{1+\exp \left[-\left(\mathrm{V}_{1 / 2}-\mathrm{V}\right) / \mathrm{k}\right]\right\}$. Both $\mathrm{V}_{1 / 2}$ and $\mathrm{k}$ also did not alter after STZ injection (Fig. $4 \mathrm{H}$ and $4 \mathrm{I} ; P>0.05$, compared with $\mathrm{CON}$, two-sample $t$ test).

\section{Streptozotocin Injection Upregulated $\mathrm{Na}_{\mathrm{v}} 1.7$ and $\mathrm{Na}_{v} 1.8$ Expression}

Anti- $\mathrm{Na}_{\mathrm{V}} 1.7$ antibody (Fig. 5A) and anti- $\mathrm{Na}_{\mathrm{V}} 1.8$ antibody (Fig. $5 \mathrm{~B})$ is labeled as $226-\mathrm{kDa}$ and $220-\mathrm{kDa}$ molecular mass protein, respectively. After STZ injection, the expressions of $\mathrm{Na}_{V} 1.7$ and $\mathrm{Na}_{\mathrm{V}} 1.8$ were increased significantly $(\mathrm{n}=4$ for each group; $P<$ 0.05 , compared with $\mathrm{CON}$, two-sample $t$ test). The relative density for $\mathrm{Na}_{V} 1.7$ was $0.62 \pm 0.09(\mathrm{n}=4)$ and $0.92 \pm 0.02(\mathrm{n}=4)$ in $\mathrm{CON}$ and STZ, respectively. The relative density for $\mathrm{Na}_{V} 1.8$ was 
A CON

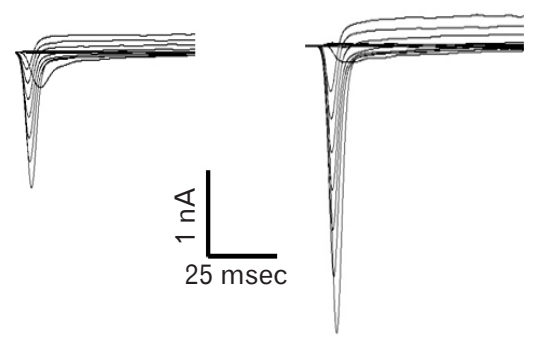

B

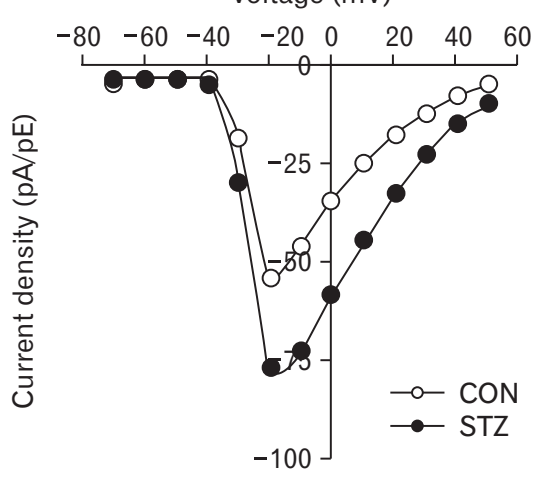

C

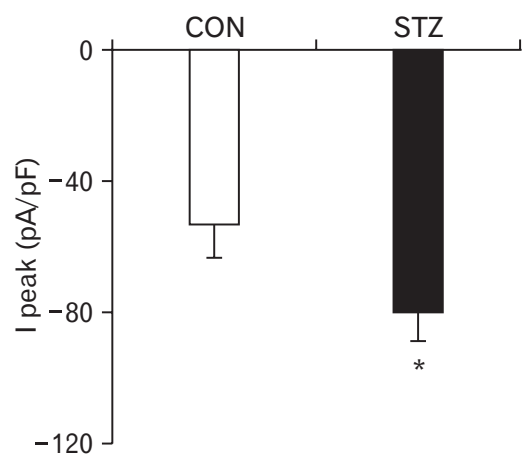

D

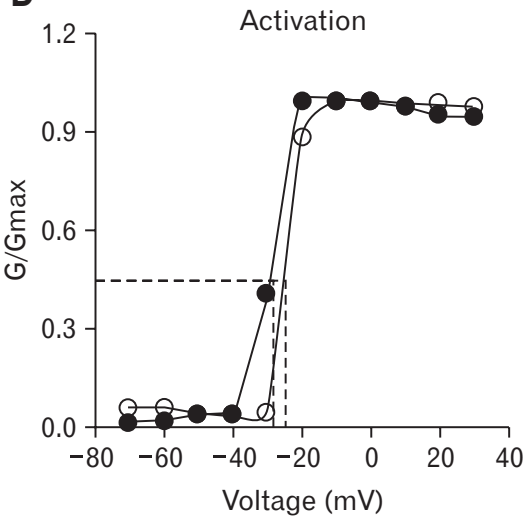

E

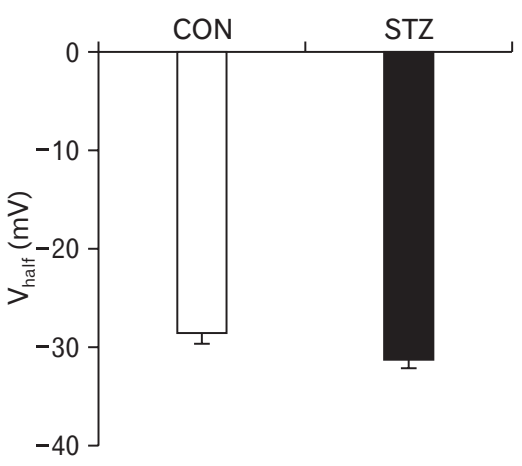

F

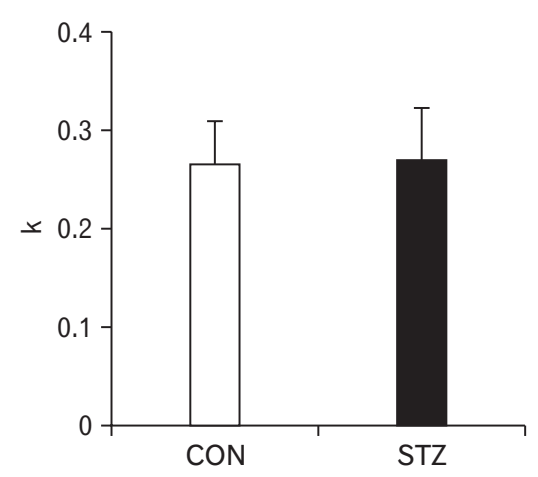

G

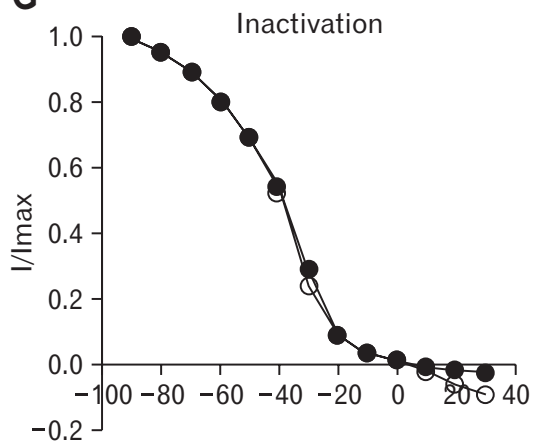

Voltage (mV)

H

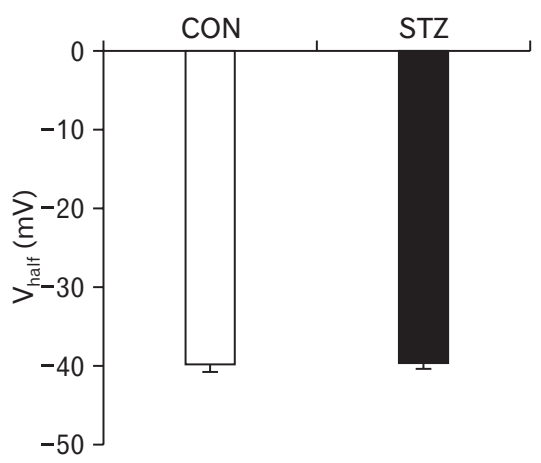

I

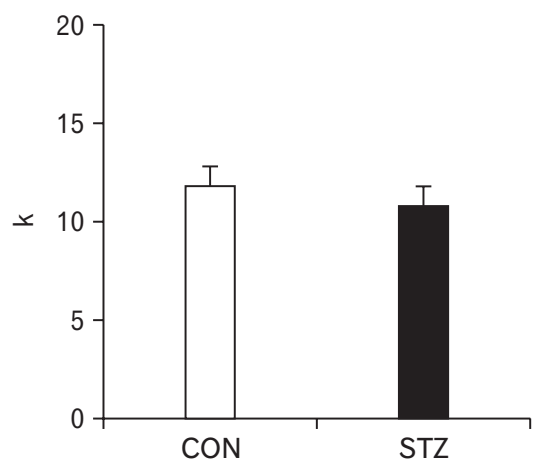

Figure 4. Enhanced sodium current density in streptozotocin (STZ)-induced diabetic rats 4 weeks after STZ injection. (A) Examples of voltagegated sodium currents recorded from control (CON; left) and STZ-treated rats (right). Membrane potential was held at $-60 \mathrm{mV}$ and voltage steps were from -70 to $+50 \mathrm{mV}$ with $10 \mathrm{mV}$ increments and $80 \mathrm{msec}$ duration. (B) I-V curves for sodium currents of colon dorsal root ganglion (DRG) neurons from CON $(\mathrm{n}=14)$ and STZ-treated rats $(\mathrm{n}=13)$. (C) Bar graphs showing the mean peak sodium current densities. STZ injection significantly increased the peak sodium currents densities ( ${ }^{\star} P<0.05$, compared with CON, Mann-Whitney test). (D) Activation curves of sodium currents were generated by stimulation steps from -70 to $+30 \mathrm{mV}$ in $10 \mathrm{mV}$ increment in DRG neuron from CON and STZ-treated rat. $(\mathrm{E}, \mathrm{F}) \mathrm{STZ}$ injection did not change the half-maximal activation potential $\left(\mathrm{V}_{1 / 2}\right)$ and the slope factor $(\mathrm{k})$ in activation of sodium current $(P>0.05$, compared with CON, Mann-Whitney test). (G) Steady-state inactivation curves of sodium currents evoked by conditional steps of various voltages from -90 to $+30 \mathrm{mV}$ with $10 \mathrm{mV}$ increment in DRG neuron from CON and STZ-treated rat. (H, I) STZ injection did not change the halfmaximal activation potential $\left(\mathrm{V}_{1 / 2}\right)$ and the slope factor $(\mathrm{k})$ in inactivation of sodium current $(P>0.05$, compared with CON, two-sample $t$ test). 
A

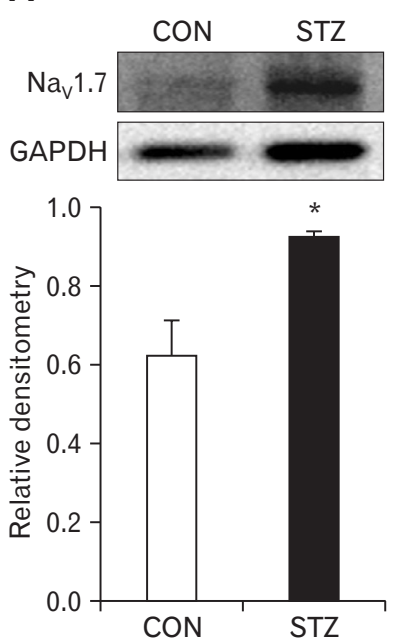

B

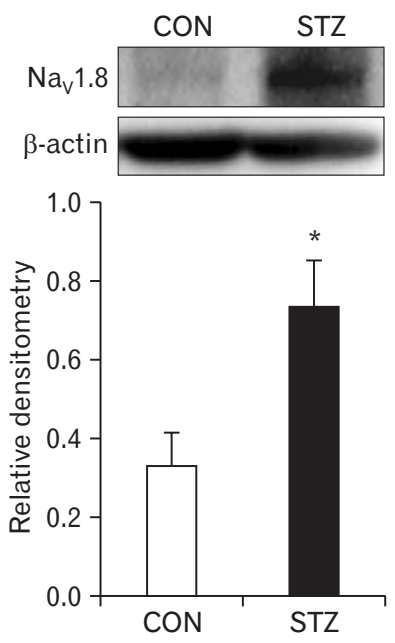

Figure 5. Upregulation in expression of $\mathrm{Na}_{\mathrm{V}} 1.7$ and $\mathrm{Na}_{\mathrm{V}} 1.8$ in dorsal root ganglions (DRGs) 4 weeks after streptozotocin (STZ) injection. (A, B) Western blots for $\mathrm{Na}_{\mathrm{V}} 1.7$ (A) and $\mathrm{Na}_{\mathrm{V}} 1.8$ (B) of T13L2 DRGs from control $(\mathrm{CON})$ and STZ-injection rats. Bar graph showed mean density relative to glyceraldehyde-3-phosphate dehydrogenase (GAPDH) for $\mathrm{Na}_{V} 1.7$ and to $\beta$-actin for $\mathrm{Na}_{V} 1.8$ from $\mathrm{CON}$ and STZ rats. STZ injection greatly enhanced expressions of $\mathrm{Na}_{\mathrm{V}} 1.7$ ( $\mathrm{n}=4$ for each group, ${ }^{*} P<0.05$, compared with $\mathrm{CON}$, two-sample $t$ test) and $\mathrm{Na}_{V} 1.8$ ( $\mathrm{n}=4$ for each group, ${ }^{*} P<0.05$, compared with CON, two-sample $t$ test) of colon DRGs.

$0.33 \pm 0.08(\mathrm{n}=4)$ and $0.73 \pm 0.12(\mathrm{n}=4)$ in CON and STZ, respectively.

\section{Discussion}

Gastrointestinal complaints are very common in diabetes mellitus. As many as $75 \%$ of diabetic patients experience one or more gastrointestinal symptoms, such as abdominal pain or discomfort, early satiety, postprandial fullness, bloating, nausea and vomiting, diarrhea or constipation, and fecal incontinence. ${ }^{32-34}$ It was also reported that diabetic patients with neuropathy had more gastrointestinal symptoms than those without neuropathy. ${ }^{35}$ The present study demonstrated that STZ injection led to colonic hypersensitivity in rats in addition to peripheral sensorimotor neuropathy $y^{36,37}$ and gastric hypersensitivity. ${ }^{18}$ This is in agreement with previous reports that diabetic rats display visceral hypersensitivity. ${ }^{6}$ We showed that a significant decrease of DT in response to CRD occurred 2 weeks after injection of STZ and continued for at least another 6 weeks within our observation time period (Fig. 1C). Meanwhile, blood glucose and body weight of rats with diabetes changed 2 weeks after STZ injection and were maintained for at least 6 weeks (Fig.

$1 \mathrm{~A}$ and $1 \mathrm{~B})$. This indicates that there is a correlation of colonic sensitivity with changes in blood glucose and body weight of rats with diabetes.

In addition to colonic hypersensitivity, we showed that STZ injection also led to a significant increase in neuronal excitability of DRG neurons innervating the colon in rats with diabetes. This conclusion is mainly based on the observations that STZ injection depolarized the resting membrane potentials, hyperpolarized the AP threshold, and decreased rheobase and increased frequency of APs evoked by 2 and 3 times rheobase stimulation and ramp current stimulation.

In order to measure cell membrane properties of neurons innervating the colon, DiI was injected into the colon wall. This ensured that all neurons recorded in the present study are those innervating the colon since DiI was absorbed by afferent fiber terminals located in the colon wall and then retrogradely transported into the neuronal bodies located in the dorsal root ganglion. The reasons that the whole-cell patch clamp recordings were performed 4 weeks after STZ injection are because the DT reached the lowest level during this period and animal suffering was minimal. To minimize the possible damage of the colon from repetitive distention of the colon, behavioral tests were performed biweekly, as described above.

Another important finding is that sodium current density was remarkably enhanced in colon DRG neurons of rats with diabetes. This could help us to explain why the excitability of DRG neurons innervating the colon was enhanced dramatically. The increase in excitability, at least in a large part, may attribute to the increase in sodium current densities. More the sodium influx led to a greater depolarization of cell membrane and enhanced excitability of DRG neurons innervating the colon. VGSCs have important roles in nociception ${ }^{8}$ and visceral pain. ${ }^{38}$ Many of the published data suggest that voltage-gated sodium channel subtypes are expressed in primary sensory neurons where they influence excitability via their role in the generation and propagation of APs. ${ }^{39}$ Nerve damage leads to alterations in expression and function of $\alpha$-subunits that in turn can enhance the excitability of sensory neurons. Changes in the excitability of sensory neurons are thought to underlie some chronic pain conditions. ${ }^{40,41}$ This result was consistent with our previous study that heterotypic intermittent stress sensitizes VGSCs in rat primary sensory neurons. ${ }^{23}$ Of note is that sensitization of VGSCs may not be the only mechanism for enhanced neuronal excitability and colonic hypersensitivity in STZ-induced diabetic rats. Indeed, Grabauskas et $\mathrm{al}^{6}$ have demonstrated that the decreased opening of $\mathrm{K}_{V} 4.2$ channels is responsible for colonic hypersensitivity in rats with diabetes. Together with previous reports, the present study 
suggests that ion channels in primary sensory neurons innervating the colon play roles in development of colonic hypersensitivity.

Although the single channel activity has yet to be investigated, our data suggests that upregulation of $\mathrm{Na}_{\mathrm{V}} 1.7$ and $\mathrm{Na}_{\mathrm{V}} 1.8$ expression may be the main cause for the increase of sodium currents in rats with diabetes. Sodium channel $\alpha$-subunits $\mathrm{Na}_{V} 1.7$ and $\mathrm{Na}_{\mathrm{V}} 1.8$ are the 2 major subunits expressed by dorsal root ganglion neurons and are thought to play an important role in peripheral neuropathy in STZ-induced diabetic rats. ${ }^{42}$ Here, we showed for the first time that STZ injection increased expression of $\mathrm{Na}_{V} 1.7$ and $\mathrm{Na}_{V} 1.8$ in DRGs. This is in agreement with previous reports that VGSCs have important roles in nociception and visceral pain. ${ }^{38,43-45}$

Based on multifarious sensitivity to tetrodotoxin (TTX), sodium currents are classified into TTX-sensitive (TTX-S) and TTXresistant (TTX-R) components. $\mathrm{Na}_{\mathrm{V}} 1.8$ is the TTX-R sodium channels while $\mathrm{Na}_{\mathrm{V}} 1.7$ mediates TTX-sensitive sodium currents. Although these two types of currents were not separated by wholecell patch clamp recordings, both $\mathrm{Na}_{V} 1.7$ (TTX-S) and $\mathrm{Na}_{V} 1.8$ (TTX-R) expression are dramatically up-regulated in STZinduced diabetic rats. ${ }^{9,23,46} \mathrm{Na}_{\mathrm{V}} 1.7$ plays an important role in signal boosting during this slow depolarization and acts as an amplifier of pain signaling. ${ }^{47}$ In diabetic peripheral neuropathy rats, $\mathrm{Na}_{\mathrm{V}} 1.7$ was significantly up-regulated in the DRG neurons and maintained at a high level until week $12 .{ }^{48} \mathrm{Na}_{\mathrm{V}} 1.8$ has also been shown involved in nociception and chronic pain. ${ }^{49-52}$ As reported by Blair and Bean, ${ }^{53}$ $\mathrm{Na}_{V} 1.8$ currents had an effect on shaping the AP waveform in nociceptive neurons due to slow inactivation rates that allows some channels to remain open following the AP upstroke. In diabetic peripheral neuropathy models, $\mathrm{Na}_{\mathrm{V}} 1.8$ protein levels increased in the DRGs in the earlier period. ${ }^{15}$ Therefore, both $\mathrm{Na}_{\mathrm{V}} 1.7$ and $\mathrm{Na}_{\mathrm{V}} 1.8$ may plan an important role in generation of diabetic colonic hypersensitivity. It is worthy to note that $\mathrm{Na}_{\mathrm{V}} 1.9$ may also play a role in our model. However, since this channel remains largely inactivated at the holding potential of $-60 \mathrm{mV}$ and the $\mathrm{V}_{\text {half }}$ of activation and inaction curves were unchanged, $\mathrm{Na}_{\mathrm{V}} 1.9$ activity may not contribute mainly to the increased sodium currents. ${ }^{45}$

To date no studies have shown the regulation mechanism underlying the sensitization of VGSCs in colonic visceral hypersensitive state in diabetic models. Clinical studies have showed that plasma TNF- $\alpha$ levels are higher in painful diabetic neuropathic (PDN) patients than in diabetes patients without chronic pain, and that the severity of pain positively correlated with the plasma TNF- $\alpha$ levels. ${ }^{14}$ In addition, the increased TNF- $\alpha$ is believed to be responsible for up-regulation of $\mathrm{Na}_{\mathrm{V}} 1.7$ in DRG neurons. ${ }^{14}$ It is therefore reasonable to hypothesize that $\mathrm{TNF}-\alpha$ may be a signifi- cant contributor to sensitization of VGSCs under PDN conditions. Nuclear factor-kappa B signal pathway may also be involved in this process since we have demonstrated that nuclear factor-kappa $\mathrm{B}$ was upregulated in rat DRGs innervating the hindpaw ${ }^{36,37}$ and the stomach. ${ }^{18}$ Moreover, both protein kinase A and protein kinase $\mathrm{C}$ activities have been shown to increase the amplitude of TTX-R sodium channel currents and to play important roles in hyperalgesia presented in PDN. ${ }^{54}$ However, it is unknown whether those abnormal signal transduction cascades occur in diabetic colonic hypersensitivity, and further research is required to investigate the regulation mechanisms. Other limitations include that the present studies did not differentiate the specific impacts from $\mathrm{Na}_{V} 1.7$ versus $\mathrm{Na}_{V} 1.8$. Further investigation of TTX-S and TTX-R sodium currents are needed.

In summary, although more evidence to link symptoms to physiology and to cellular changes is needed, the present study demonstrates that diabetes induced by STZ produces a significant colonic hypersensitivity, which is likely to be mediated by enhanced function and expression of VGSCs (ie, $\mathrm{Na}_{V} 1.7$ and $\mathrm{Na}_{V} 1.8$ subunits) in primary sensory neurons, thus highlighting a potential therapeutic target for treatment for diabetic abdominal pain in patients with diabetes.

Financial support: This work was supported by grants from the National Natural Science Foundation of China (81230024, 81471137, 31271258, 81471041, and 31400947) and Priority Academic Program Development of Jiangsu Higher Education Institutions (PAPD). This project is subject to funding from the preponderant clinic group project of the Second Affiliated Hospital of Soochow University (XKQ2015001 and XKQ2015008). This work was also supported by a grant from Natural Science Foundation of Jiangsu Higher Education Institutions (13KJB180020). The funders had no role in the study design, data collection and analysis, decision to publish, or preparation of the manuscript.

\section{Conflicts of interest: None.}

Author contributions: Ji Hu and Zhen-Yuan Song: planning and performing the experiments, and drafting manuscript; HongHong Zhang: designing the experiments, analysis, and interpretation of data; Xin Qin and Shufen Hu: performing the experiments; Xinghong Jiang: analysis of data; and Guang-Yin Xu: conducting the study and revision of the manuscript. 


\section{References}

1. Caruana BJ, Wald A, Hinds JP, Eidelman BH. Anorectal sensory and motor function in neurogenic fecal incontinence. Comparison between multiple sclerosis and diabetes mellitus. Gastroenterology 1991;100:465470.

2. Wald A, Tunuguntla AK. Anorectal sensorimotor dysfunction in fecal incontinence and diabetes mellitus. Modification with biofeedback therapy. N Engl J Med 1984;310:1282-1287.

3. Samsom M, Akkermans LM, Jebbink RJ, van Isselt $H$, vanBergeHenegouwen GP, Smout AJ. Gastrointestinal motor mechanisms in hyperglycaemia induced delayed gastric emptying in type I diabetes mellitus. Gut 1997;40:641-646.

4. Owyang C. Phenotypic switching in diabetic gastroparesis: mechanism directs therapy. Gastroenterology 2011;141:1134-1137.

5. McHugh JM, McHugh WB. Diabetes and peripheral sensory neurons: what we don't know and how it can hurt us. AACN Clin Issues 2004;15: 136-149.

6. Grabauskas G, Heldsinger A, Wu X, Xu D, Zhou S, Owyang C. Diabetic visceral hypersensitivity is associated with activation of mitogenactivated kinase in rat dorsal root ganglia. Diabetes 2011;60:1743-1751.

7. Said G. Diabetic neuropathy: an update. J Neurol 1996;243:431-440.

8. Peters $\mathrm{CH}$, Ruben PC. Introduction to sodium channels. Handb Exp Pharmacol 2014;221:1-6.

9. Strickland IT, Martindale JC, Woodhams PL, Reeve AJ, Chessell IP, McQueen DS. Changes in the expression of $\mathrm{Na}_{V} 1.7, \mathrm{Na}_{\mathrm{V}} 1.8$ and $\mathrm{Na}_{\mathrm{V}} 1.9$ in a distinct population of dorsal root ganglia innervating the rat knee joint in a model of chronic inflammatory joint pain. Eur J Pain 2008;12:564572 .

10. Huang CP, Chen HN, Su HL, et al. Electroacupuncture reduces carrageenan- and CFA-induced inflammatory pain accompanied by changing the expression of $\mathrm{Na}_{V} 1.7$ and $\mathrm{Na}_{V} 1.8$, rather than $\mathrm{Na}_{V} 1.9$, in mice dorsal root ganglia. Evid Based Complement Alternat Med 2013;2013:312184.

11. McGowan E, Hoyt SB, Li X, Lyons KA, Abbadie C. A peripherally acting $\mathrm{Na}_{V} 1.7$ sodium channel blocker reverses hyperalgesia and allodynia on rat models of inflammatory and neuropathic pain. Anesth Analg 2009;109:951-958.

12. Ghelardini C, Desaphy JF, Muraglia M, et al. Effects of a new potent analog of tocainide on $\mathrm{hNa}_{\mathrm{V}} 1.7$ sodium channels and in vivo neuropathic pain models. Neuroscience 2010;169:863-873.

13. Sleeper AA, Cummins TR, Dib-Hajj SD, et al. Changes in expression of two tetrodotoxin-resistant sodium channels and their currents in dorsal root ganglion neurons after sciatic nerve injury but not rhizotomy. J Neurosci 2000;20:7279-7289.

14. Huang Y, Zang Y, Zhou L, Gui W, Liu X, Zhong Y. The role of TNFalpha/NF-kappa B pathway on the up-regulation of voltage-gated sodium channel $\mathrm{Na}_{V} 1.7$ in DRG neurons of rats with diabetic neuropathy. Neurochem Int 2014;75:112-119.

15. Craner MJ, Klein JP, Renganathan M, Black JA, Waxman SG. Changes of sodium channel expression in experimental painful diabetic neuropathy. Ann Neurol 2002;52:786-792.
16. Zhang HH, Hu J, Zhou YL, et al. Promoted interaction of nuclear factor-kappaB with demethylated cystathionine-beta-synthetase gene contributes to gastric hypersensitivity in diabetic rats. J Neurosci 2013;33:9028-9038.

17. Zhang JL, Yang JP, Zhang JR, et al. Gabapentin reduces allodynia and hyperalgesia in painful diabetic neuropathy rats by decreasing expression level of $\mathrm{Na}_{\mathrm{V}} 1.7$ and p-ERK1/2 in DRG neurons. Brain Res 2013;1493: 13-18.

18. Cheng KI, Wang HC, Chuang YT, et al. Persistent mechanical allodynia positively correlates with an increase in activated microglia and increased P-p38 mitogen-activated protein kinase activation in streptozotocininduced diabetic rats. Eur J Pain 2014;18:162-173.

19. Winston J, Shenoy M, Medley D, Naniwadekar A, Pasricha PJ. The vanilloid receptor initiates and maintains colonic hypersensitivity induced by neonatal colon irritation in rats. Gastroenterology 2007;132:615-627.

20. Xu GY, Shenoy M, Winston JH, Mittal S, Pasricha PJ. P2X receptormediated visceral hyperalgesia in a rat model of chronic visceral hypersensitivity. Gut 2008;57:1230-1237.

21. Li L, Xie R, Hu S, et al. Upregulation of cystathionine beta-synthetase expression by nuclear factor-kappa $\mathrm{B}$ activation contributes to visceral hypersensitivity in adult rats with neonatal maternal deprivation. Mol Pain 2012;8:89.

22. Xu GY, Winston JH, Shenoy M, Zhou S, Chen JD, Pasricha PJ. The endogenous hydrogen sulfide producing enzyme cystathionine-beta synthase contributes to visceral hypersensitivity in a rat model of irritable bowel syndrome. Mol Pain 2009;5:44.

23. Wang Y, Qu R, Hu S, Xiao Y, Jiang X, Xu GY. Upregulation of cystathionine beta-synthetase expression contributes to visceral hyperalgesia induced by heterotypic intermittent stress in rats. PLoS One 2012;7: e53165.

24. Hunt SP, Mantyh PW. The molecular dynamics of pain control. Nat Rev Neurosci 2001;2:83-91.

25. Xu GY, Huang LY. Peripheral inflammation sensitizes P2X receptormediated responses in rat dorsal root ganglion neurons. J Neurosci 2002; 22:93-102.

26. Harty TP, Dib-Haij SD, Tyrrell L, et al. Na(V)1.7 mutant A863P in erythromelalgia: effects of altered activation and steady-state inactivation on excitability of nociceptive dorsal root ganglion neurons. J Neurosci 2006;26:12566-12575.

27. Herzog RI, Cummins TR, Waxman SG. Persistent TTX-resistant $\mathrm{Na}^{+}$ current affects resting potential and response to depolarization in simulated spinal sensory neurons. J Neurophysiol 2001;86:1351-1364.

28. Stewart T, Beyak MJ, Vanner S. Ileitis modulates potassium and sodium currents in guinea pig dorsal root ganglia sensory neurons. J Physiol 2003;552(Pt 3):797-807.

29. Singh JN, Jain G, Sharma SS. In vitro hyperglycemia enhances sodium currents in dorsal root ganglion neurons: an effect attenuated by carbamazepine. Neuroscience 2012;232:64-73.

30. Cummins NW, Deziel PJ, Abraham RS, Razonable RR. Deficiency of cytomegalovirus (CMV)-specific $\mathrm{CD} 8{ }^{+} \mathrm{T}$ cells in patients presenting with late-onset $\mathrm{CMV}$ disease several years after transplantation. Transpl Infect Dis 2009;11:20-27. 
31. Hu S, Xiao Y, Zhu L, et al. Neonatal maternal deprivation sensitizes voltage-gated sodium channel currents in colon-specific dorsal root ganglion neurons in rats. Am J Physiol Gastrointest Liver Physiol 2013;304: G311-G321.

32. Watkins CC, Sawa A, Jaffrey S, et al. Insulin restores neuronal nitric oxide synthase expression and function that is lost in diabetic gastropathy. J Clin Invest 2000;106:373-384.

33. Park KS. Impact of myenteric plexus alterations on diabetes related gastrointestinal dysmotility. J Neurogastroenterol Motil 2013;19:121-123.

34. Demedts I, Masaoka T, Kindt S, et al. Gastrointestinal motility changes and myenteric plexus alterations in spontaneously diabetic biobreeding rats. J Neurogastroenterol Motil 2013;19:161-170.

35. Lee SD, Keum B, Chun HJ, Bak YT. Gastroesophageal reflux disease in Type II diabetes mellitus with or without peripheral neuropathy. J Neurogastroenterol Motil 2011;17:274-278.

36. Xu GY, Li G, Liu N, Huang LY. Mechanisms underlying purinergic $\mathrm{P} 2 \mathrm{X} 3$ receptor-mediated mechanical allodynia induced in diabetic rats. Mol Pain 2011;7:60.

37. Shi L, Zhang HH, Xiao Y, Hu J, Xu GY. Electroacupuncture suppresses mechanical allodynia and nuclear factor kappa B signaling in streptozotocin-induced diabetic rats. CNS Neurosci Ther 2013;19:8390.

38. Qi FH, Zhou YL, Xu GY. Targeting voltage-gated sodium channels for treatment for chronic visceral pain. World J Gastroenterol 2011;17:23572364.

39. Lindia JA, Köhler MG, Martin WJ, Abbadie C. Relationship between sodium channel $\mathrm{Na}_{\mathrm{V}} 1.3$ expression and neuropathic pain behavior in rats. Pain 2005;117:145-153.

40. Wood JN, Abrahamsen B, Baker MD, et al. Ion channel activities implicated in pathological pain. Novartis Found Symp 2004;261:32-40; discussion 40-54.

41. Nassar MA, Levato A, Stirling LC, Wood JN. Neuropathic pain develops normally in mice lacking both $\mathrm{Na}_{\mathrm{V}} 1.7$ and $\mathrm{Na}_{\mathrm{V}} 1.8$. Mol Pain 2005;1:24.

42. Sun W, Miao B, Wang XC, et al. Reduced conduction failure of the main axon of polymodal nociceptive $\mathrm{C}$-fibres contributes to painful diabetic neuropathy in rats. Brain 2012;135(Pt 2):359-375.

43. Gold MS, Zhang L, Wrigley DL, Traub RJ. Prostaglandin $\mathrm{E}_{2}$ modulates TTX-R $I_{\mathrm{Na}}$ in rat colonic sensory neurons. J Neurophysiol 2002;88:1512-1522.

44. Yoshimura N, Seki S, Novakovic SD, et al. The involvement of the tetrodotoxin-resistant sodium channel $\mathrm{Na}(\mathrm{v}) 1.8(\mathrm{PN} 3 / \mathrm{SNS})$ in a rat model of visceral pain. J Neurosci 2001;21:8690-8696.

45. Qu R, Tao J, Wang Y, et al. Neonatal colonic inflammation sensitizes voltage-gated $\mathrm{Na}^{+}$channels via upregulation of cystathionine betasynthetase expression in rat primary sensory neurons. Am J Physiol Gastrointest Liver Physiol 2013;304:G763-G772.

46. Lai J, Gold MS, Kim CS, et al. Inhibition of neuropathic pain by decreased expression of the tetrodotoxin-resistant sodium channel, $\mathrm{Na}_{\mathrm{V}} 1.8$. Pain 2002;95:143-152

47. Krafte DS, Bannon AW. Sodium channels and nociception: recent concepts and therapeutic opportunities. Curr Opin Pharmacol 2008;8:5056.

48. Huang Y, Zang Y, Zhou L, Gui W, Liu X, Zhong Y. The role of TNFalpha/NF-kappa B pathway on the up-regulation of voltage-gated sodium channel $\mathrm{Na}_{\mathrm{V}} 1.7$ in DRG neurons of rats with diabetic neuropathy. Neurochem Int 2014;75:112-119.

49. Dong XW, Goregoaker S, Engler H, et al. Small interfering RNAmediated selective knockdown of $\mathrm{Na}_{\mathrm{V}} 1.8$ tetrodotoxin-resistant sodium channel reverses mechanical allodynia in neuropathic rats. Neuroscience 2007;146:812-821.

50. Thakor DK, Lin A, Matsuka Y, et al. Increased peripheral nerve excitability and local $\mathrm{Na}_{\mathrm{V}} 1.8 \mathrm{mRNA}$ up-regulation in painful neuropathy. Mol Pain 2009;5:14.

51. Gold MS, Weinreich D, Kim CS, et al. Redistribution of $\mathrm{Na}(\mathrm{V}) 1.8$ in uninjured axons enables neuropathic pain. J Neurosci 2003;23:158-166.

52. Jarvis MF, Honore P, Shieh CC, et al. A-803467, a potent and selective $\mathrm{Na}_{\mathrm{V}} 1.8$ sodium channel blocker, attenuates neuropathic and inflammatory pain in the rat. Proc Natl Acad Sci USA 2007;104:8520-8525.

53. Blair NT, Bean BP. Roles of tetrodotoxin (TTX)-sensitive $\mathrm{Na}^{+}$current, TTX-resistant $\mathrm{Na}^{+}$current, and $\mathrm{Ca}^{2+}$ current in the action potentials of nociceptive sensory neurons. J Neurosci 2002;22:10277-10290.

54. Hirade M, Yasuda H, Omatsu-Kanbe M, Kikkawa R, Kitasato H. Tetrodotoxin-resistant sodium channels of dorsal root ganglion neurons are readily activated in diabetic rats. Neuroscience 1999;90:933-939. 